\title{
The ubiquitous terpene geosmin is a warning chemical
}

3 Authors

4 Liana Zaroubi ${ }^{1}$, Imge Ozugergin ${ }^{2}$, Karina Mastronardi ${ }^{2}$, Anic Imfeld ${ }^{1}$, Chris Law ${ }^{2}$, Yves Gélinas ${ }^{1}$, Alisa

5 Piekny ${ }^{2} \&$ Brandon L. Findlay ${ }^{1, *}$

6

7 Affiliations

$8{ }^{1}$ Department of Chemistry and Biochemistry, Concordia University, Montreal, Québec, Canada

$9 \quad{ }^{2}$ Department of Biology, Concordia University, Montreal, Québec, Canada

$10 *$ Correspondence to: Brandon L. Findlay, Email: brandon.findlay@concordia.ca

11

\section{Abstract}

13 Known as the smell of earth after rain, geosmin is an odorous terpene detectable by humans at

14 picomolar concentrations. Geosmin production is heavily conserved in actinobacteria, myxobacteria,

15 cyanobacteria, and some fungi, but its biological activity is poorly understood. We theorized that

16 geosmin was an aposematic signal used to indicate the unpalatability of toxin-producing microbes,

17 discouraging predation by eukaryotes. Consistent with this hypothesis we found that geosmin and the

18 related terpene 2-methylisoborneol reduced predation of Streptomyces coelicolor and Myxococcus

19 xanthus by the bacteriophagous Caenorhabditis elegans. Predation was restored by the removal of both

20 terpene biosynthetic pathways or deletion of the $C$. elegans ASE sensory neuron, and resulted in the

21 death of the nematodes. Geosmin itself was non-toxic. This is the first warning chemical to be identified

22 in bacteria or fungi, and suggests molecular signalling affects microbial predator-prey interactions in a

23 manner similar to the well-studied visual markers of poisonous animal prey. 


\section{Introduction}

25

26

27

Few natural products are as widespread as geosmin, the smell of wet earth ${ }^{1}$. Its chief producers in the soil, the saprophytic bacterial phylum Actinobacteria and predatory/saprophytic bacterial order Myxococcales, are found on every continent, including Antarctica ${ }^{2,3}$. Geosmin is also a common contaminant in drinking water and farmed fish ${ }^{4,5}$, produced by aquatic equivalents of these soil bacteria and by cyanobacteria ${ }^{4}$. Though chiefly a prokaryotic metabolite, geosmin is also produced by a range of fungi ${ }^{6,7}$, and is found in the peel of beets ${ }^{8}$. Geosmin production is heavily conserved ${ }^{9-12}$, and frequently accompanied by another odorous terpene, 2-methylisoborneol (Figure 1A) ${ }^{10,13}$.

The breadth of geosmin producers and their varied ecological niches complicates assignment of the compound's broader function. Geosmin repels egg-laying Drosophila melanogaster, which has a dedicated olfactory sensory neuron for geosmin detection ${ }^{14}$, and attracts mosquitos and ants ${ }^{8,15}$. Geosmin attracts springtails to sporulating Streptomyces colonies, which then eat the bacteria and help disperse bacterial spores ${ }^{16}$, but this interaction would be of limited utility in aquatic environments ${ }^{12}$. Due to differing primary nutrient sources, life cycles, cell wall structures, predators, and symbionts the principal geosmin producers have few features in common ${ }^{9,10,12}$, but all produce a wealth of non-geosmin secondary metabolites ${ }^{17}$. Many of these bioactive compounds inhibit the growth of prokaryotes or eukaryotes ${ }^{17,18}$, and may be used in nature to deter competitors and predators ${ }^{19-22}$.

In the animal kingdom, toxic prey advertise their unpalatability through the use of warning colours ${ }^{23}$. These bright colours make the prey more conspicuous, but when combined with 
45 negative stimuli they deter predation through learned responses ${ }^{24,25}$. To date no warning colours or other aposematic signals have been identified in prokaryotes, though olfactory

47 signals may be used to reduce scavenging of nutrient-rich insects killed by entomopathogenic 48 bacteria ${ }^{26}$.

We propose that geosmin is a warning chemical, expressed by actinobacteria, myxobacteria, and cyanobacteria to advertise the production of toxic secondary metabolites. Commensurate with this hypothesis geosmin was non-toxic to the bacteriophagous nematode Caenorhabditis elegans, and did not prevent the worms from preying on non-toxinogenic Escherichia coli cells. Geosmin also did not act as a nematode repellent or attractant, but through interactions mediated by the ASE gustatory neuron triggered a distinct crawling behaviour with

55 characteristics of both roaming and dwelling movement. Geosmin and 2-methylisoborneol significantly reduced nematode grazing on Streptomyces coelicolor colonies, though the terpenes were non-toxic to C. elegans. Grazing in the absence of the terpenes or by C. elegans

58 mutants that lacked the ASE gustatory neuron triggered sporulation and the expression of a

59 toxic secondary metabolite by S. coelicolor, while consumption of S. coelicolor or M. xanthus led to a $C$. elegans stress behaviour and the death of the worms. The use of geosmin as a warning

61 chemical that deters predation by signalling the presence of toxic secondary metabolites is in

62 line with previous reports of its attractant and repellant activities, and explains the high

63 prevalence of geosmin biosynthetic genes in evolutionarily disparate microbes well known for 64 their toxic natural products. 


\section{Results}

\section{Geosmin is produced during growth}

69 To determine when geosmin provides the most benefit to its producers we characterized the production of geosmin as a function of growth in the predatory bacteria M. xanthus DK1622. In

71 liquid media geosmin concentrations rose during the bacteria's exponential phase and

72 plateaued during early stationary phase, decreasing thereafter (Figure 1B). Fractionation of the

73 cells and media and subsequent extraction with ethyl acetate confirmed that the majority of

74 geosmin was excreted from the cell (Table S1). This production of geosmin during exponential

75 phase suggests the compound is relevant when $M$. xanthus is hunting other bacteria.

\section{Geosmin does not aid protein degradation}

77 Myxobacteria and actinobacteria obtain nutrients through the degradation of organic matter,

78 either as saprophytes or predators ${ }^{2,27}$. After confirming that geosmin did not inhibit the growth

79 of Gram-negative or Gram-positive bacteria at physiologically relevant concentrations (Table

80 S2), we examined the effect of geosmin on protease activity. Geosmin slightly reduced

81 degradation of FTC-casein by the digestive enzymes excreted by M. xanthus DK1622 ${ }^{28}$, and had

82 no effect on degradation by a well-characterized human protease, trypsin (Figure S1).

83 As geosmin associates with membrane proteins in cyanobacteria ${ }^{4}$, we postulated that it might

84 stabilize hydrophobic digestive enzymes in $M$. xanthus. To evaluate this function we measured 
85 the effect of geosmin on heat-induced denaturation of the model hydrophobic protein bovine serum albumin (BSA). Geosmin had no discernable effect on BSA stability as measured by

87 circular dichroism, either at elevated temperatures or on heating or cooling (Figure S2).

89 To determine if geosmin inhibited $M$. xanthus predators we tested its toxicity against the nematode $C$. elegans. In addition to their key role in understanding the development and function of the nervous system ${ }^{29}$, nematodes are prevalent in soils across the globe and their

92 grazing impacts microbial abundance and diversity ${ }^{30,31}$. When mixed into agar geosmin had no

93 effect on the viability of adult hermaphrodite nematodes over a 24-hour period (Figure 1C,

94 Figure S3A), and did not appear to act as a chemoattractant or chemorepellent (Table S3).

95 Grazing on the standard laboratory C. elegans prey, E. coli OP50, was similarly unaffected by

96 geosmin, even at terpene concentrations well above that produced by M. xanthus, as

97 evidenced by deep tracks in the E. coli lawn after $24 \mathrm{hr}$ of incubation (Figure S3B-C).

However, geosmin strongly altered the worms' movement. On NGM agar plates adult

99 hermaphrodites exhibited clear roaming behaviour ${ }^{32}$, with long, slightly arching pathways and

100 few distinct turns or reversals. On NGM-geosmin plates the nematodes immediately began to

101 move erratically, with many abrupt turns. Unlike traditional dwelling behaviour or responses to

102 other bacterial metabolites 32,33 , these worms moved faster than control worms and did not

103 frequently reverse direction (Table S4, Files S1-S2). To quantify this change in behaviour we

104 followed the movement of the worms in Imaris and WormLab, measuring significant changes in

105 track linearity, peristaltic speed, and head movement periodicity (Figure 1D, Table S4). 
To determine how geosmin was causing these changes we compared the movement of a range of $C$. elegans mutants in the presence or absence of geosmin. A mutant deficient in chemosensation, C. elegans NL2105, exhibit similar behaviour in the presence and absence of geosmin, indicating that the terpene's effect was mediated by the host chemosensation machinery (Figure 1D, Files S3-S4) ${ }^{34}$. The modified dwelling behaviour was retained in worms deficient in the sensing of volatile attractants and repellents (mutants lacking AWA and AWB neurons, Figure 1D), suggesting that geosmin is not detected by the nematode olfactory system, but lost in worms lacking the gustatory neuron ASE. ASE has been previously linked to the sensing of water-soluble attractants and movement away from food as prey populations decline ${ }^{35,36}$.

\section{Geosmin deters feeding on its producers}

As geosmin did not limit predation of $E$. coli by $C$. elegans, to test its effect in situ we added $C$. elegans to plates containing colonies of S. coelicolor, using both the wildtype S. coelicolor M145 and mutant strains lacking production of geosmin (J3003) and both geosmin and 2methylisoborneol (J2192) ${ }^{16,37}$. When C. elegans N2 was added to S. coelicolor M145 or J3003 the majority of worms localized outside of the bacterial colonies after $4 \mathrm{hr}$ (Figure 2A). When added to S. coelicolor $\mathrm{J} 2192$ worms were predominantly found within the bacterial colony at the $2 \mathrm{hr}$ and $4 \mathrm{hr}$ mark. Worms lacking the ASE neuron, C. elegans PR674, localized within all three bacterial strains at all time points (Figure 2B). In all experiments nematodes consumed the bacteria, as noted by the presence of red bacteria within the nematode pharynx (Figure 2E). The addition of worms lead to rapid sporulation of S. coelicolor and the production of the toxic 
127 bacterial metabolite actinorhodin (Figure $2 \mathrm{G})^{38}$. The majority of worms within bacterial

128 colonies at the $24 \mathrm{hr}$ mark were coated in white bacterial spores, and either exhibited distress

129 behaviour (File S5), or appeared dead. The movement of worms into and out of bacterial

130 colonies did disperse some bacterial spores (Figure 2G), but given the high toll on both bacterial

131 growth and worm viability the overall effect of nematode predation was detrimental to both

132 nematodes and bacteria.

133 To ensure the non-terpene metabolite profile of S. coelicolor mutants J3003 and J2192 did not

134 meaningfully differ from that of the wildtype we conducted a series of add-in experiments.

135 Geosmin and 2-methylisoborneol were added alone or in combination to colonies of S.

136 coelicolor J2192, at concentrations approximating their physiological values ${ }^{4,16}$. Geosmin or 2-

137 methylisoborneol was sufficient to significantly reduce the number of worms in bacterial

138 colonies at the $2 \mathrm{hr}, 4 \mathrm{hr}$, and $24 \mathrm{hr}$ mark (Figure 2C). At $24 \mathrm{hrs}$ few worms were found in

139 bacterial colonies treated with geosmin and 2-methylisoborneol, in line with the co-occurrence

140 of geosmin and 2-methylisoborneol biosynthetic genes in actinobacteria and cyanobacteria, but

141 at the concentration of terpenes in our study the effect was not statistically distinct from 2-

142 methylisoborneol or geosmin alone ${ }^{10,12}$.

143 To determine if the reduction in predation that we observed was limited to S. coelicolor we

144 repeated our assay with $M$. xanthus DK1622. As with the Streptomyces, C. elegans N2 localized

145 outside the $M$. xanthus colony at the $24 \mathrm{hr}$ mark, despite the latter's swarming movement over

146 the agar plate (Figure 2D). C. elegans PR674 showed no such aversion, resulting again in the

147 death of both predator and bacterial prey (Figure 2F). 


\section{Discussion}

150 The high prevalence of geosmin synthase genes across unrelated bacteria and fungi suggests

151 that geosmin is key to the fitness of a broad range of microorganisms. Here we propose that

152 geosmin is a widespread warning chemical, used to advertise the toxicity of its producers and

153 deter predation. Consistent with this role geosmin is produced during the mobile hunting phase

154 of M. xanthus growth, and is actively excreted from the cell (Figure 1B, Table S1). Production in

155 Streptomyces spp. is more complex, as the geosmin precursor isopentenyl pyrophosphate is

156 produced by both the methylerythritol phosphate (MEP) and mevalonate pathways in this

157 genus ${ }^{4}$, and the two pathways are differentially regulated between strains and growth phases

$158 \quad 39,40$. Cyanobacteria stockpile geosmin and 2-methylisoborneol during exponential growth and

159 stationary phase, and release the terpenes as they die ${ }^{41}$.

160 To act as an aposematic signal geosmin must be detected by potential microbial predators. The

161 bacteriophagous $C$. elegans detected geosmin through the gustatory neuron, ASE, switching to

162 a behaviour characterized by frequent changes in direction and high movement speeds (Figure

163 1D, Table S4, Files S1-S4). In the presence of S. coelicolor, when worms were able to sense

164 geosmin and either geosmin or 2-methylisoborneol was present this change in behaviour

165 resulted in significantly fewer worms in the bacterial colonies (Figure 2A-B). Similar results were

166 obtained when geosmin or 2-methylisoborneol was added to a S. coelicolor mutant deficient in

167 the production of these terpenes, and when worms were added to geosmin-producing $M$.

168 xanthus DK1622 (Figure 2C-D). Geosmin was not only non-toxic to these worms (Figure 1C), but 
by altering $C$. elegans's feeding behaviour geosmin prevented the worms from coating their bodies in bacterial spores or ingesting toxic bacterial metabolites. As with Drosophila and $A$.

171 aegypti ${ }^{8,14}$, this effect was mediated by the predator's own chemosensory system.

172 The use of geosmin as an aposematic signal may explain its reported effects on other

173 eukaryotes and its prevalence across a range of unrelated microbes. Geosmin attracts

174 Solenopsis invicta because the terpene reliably indicates the presence of Streptomyces spp.,

175 and the toxic metabolites produced by these bacteria protect ant colonies from fungal

176 infections ${ }^{15}$. Similarly, geosmin discourages egg laying by Drosophila, whose young are

177 susceptible to bacterial toxins ${ }^{14}$, while also signalling the presence of edible cyanobacteria to

178 the more toxin-resistant $A$. aegypti ${ }^{8,42}$. In principle, acquisition of geosmin synthase by any

179 toxin-producing microbe could recapitulate the aposematic phenotype, favouring lateral gene

180 transfer between evolutionarily unrelated species and the evolution of Müllerian mimics ${ }^{43,44}$.

181 Other aposematic signals exhibit positive frequency-dependent selection ${ }^{45}$, and the evolution

182 of Müllerian mimics in bacteria likely favours the further lateral gene transfer of geosmin

183 synthase. The ubiquity of geosmin in natural environments ensures few predators are naïve to

184 the signal, while those that ignore it likely experience consistent fitness penalties from preying

185 on toxic geosmin producers.

186 Geosmin did not prevent $C$. elegans from feeding on $E$. coli but heavily reduced grazing on $S$.

187 coelicolor or $M$. xanthus (Figure 2), suggesting that aversion requires both the terpene and a

188 negative stimuli ${ }^{33}$. Microbial predators can discern between adjacent toxin-producing and non-

189 toxic bacteria ${ }^{46}$, and the ability of geosmin to deter but not protect against predation may 
prevent the emergence of Batesian mimics that express only the terpene. While $C$. elegans reacted to geosmin in the absence of S. coelicolor or M. xanthus (Figure 1D), it is unclear if the avoidance of toxin-producing bacteria was learned or innate. Higher eukaryotes can learn to associate aposematic signals with unpalatability ${ }^{24,47}$, and while bacterial predators are significantly less complex, both $C$. elegans and amoeba can link sensory cues to past events ${ }^{48,49}$.

In conclusion, geosmin is detected by the predatory nematode C. elegans through the gustatory neuron ASE. Geosmin is non-toxic to this species, but nematodes strongly avoid geosminproducing bacteria. When geosmin production was eliminated or the ASE neuron was disabled C. elegans became coated in bacterial spores and ingested toxic secondary metabolites. Concurrently, bacterial fitness declined through nematode feeding and the conversion of vegetative cells to senescent spores. Geosmin thus acts as an aposematic signal, honestly and reliably advertising the unpalatability of its producers and providing a mutual benefit to predator and prey. Geosmin is the first warning chemical to be identified in bacteria, and it not only shapes bacterial predator-prey interactions but also appears to mediate interactions between eukaryotes and bacteria across the globe.

\section{Materials and Methods}

\section{Strains and cultivation}

Bacteria. Klebsiella aerogenes ATCC 13048 was acquired from the American Type Culture Collection (ATCC). Escherichia coli MG1655 and Burkholderia thailandensis E 264 were a gift from Eric Déziel, INRS-IAF. Myxococcus xanthus DK1622, Micrococcus luteus DSM 20030 
211 and Bacillus subtilis DSM 10 were obtained from the Leibniz Institute DSMZ-German

212 Collection of Microorganisms and Cell Cultures. Streptomyces coelicolor M145, J3003 and

213 J2192 originated from the John Innes Centre, Norwich, UK, and were gifts from Dr. Klas Flärdh.

214 Escherichia coli OP50 was obtained from the Caenorhabditis Genetics Center (CGC) which is

215 funded by NIH Office of Research Infrastructure Programs (P40 OD010440).

217 M. luteus, B. subtilis, B. thailandensis, K. aerogenes and E. coli were grown in Luria-Bertani

218 (LB) media, at $30^{\circ} \mathrm{C}\left(37^{\circ} \mathrm{C}\right.$ for $E$. coli $)$ rotating at $225 \mathrm{rpm}$ for liquid cultures. Bacterial isolates

219 were streaked on $1.5 \%$ agar LB plates and placed at $30{ }^{\circ} \mathrm{C}$ for $24 \mathrm{hrs}\left(37^{\circ} \mathrm{C}\right.$ for $16 \mathrm{hrs}$ for E. coli)

220 prior to experiments. M. xanthus DK1622 was grown in $1 \%$ CTT at $30{ }^{\circ} \mathrm{C}$ and $225 \mathrm{rpm}$.

221 Bacterial isolates were streaked on $1.5 \%$ agar CTT plates and placed at $30{ }^{\circ} \mathrm{C}$ for 3 days prior to

222 experiments. Streptomyces coelicolor M145, J3003 and J2192 were grown at $30{ }^{\circ} \mathrm{C}$ in Tryptic

223 Soy Broth (TSB) rotating at $225 \mathrm{rpm}$ and isolates were streaked on 1.5\% agar Tryptic Soy Agar

224 (TSA). Growth curves for M. xanthus DK1622 were generated by performing daily OD 600

225 measurements using a Varian Cary 100 Bio UV-vis spectrophotometer.

226 Caenorhabditis elegans. The $C$. elegans lineages were maintained on nematode growth medium

227 (NGM) plates with E. coli OP50 at $20^{\circ} \mathrm{C}$ as per standard protocol ${ }^{50}$. The wild type $\mathrm{N} 2$ and

228 mutant strains BR5514 (tax-2(p671);tax-4(p678)), CE1258 (eat-16(ep273)), CX2065 (odr-

229 1(n1936)), CX2205 (odr-3(n2150)), CX5893 (kyIs140 I; ceh-36(ky646)), NL2105 (gpa-3(pk35)

230 odr-3(n1605)) and PR674 (che-1(p674)) were obtained from the Caenorhabditis Genetics Center

231 (CGC) which is funded by NIH Office of Research Infrastructure Programs (P40 OD010440).

232 Gravid nematodes were age synchronized and cleaned from bacterial and fungal contaminants 
233

234

235

236

237

238

239

240

241

242

243

244

245

246

247

248

249

250

251

252

253

254

255

using a bleaching mixture $(2.5 \% \mathrm{NaClO}, 0.5 \mathrm{M} \mathrm{NaOH})$ before each experiment, as previously described ${ }^{50}$. All C. elegans experiments were conducted using a standard stereomicroscope.

Chemicals. ( \pm )-Geosmin standard was obtained from Sigma-Aldrich, (-)-geosmin was purchased from FUJIFILM WAKO chemicals. Bovine serum albumin, levamisole, (1R)-(+)-camphor and the 3.0 M methylmagnesium bromide solution in diethyl ether (189898) were obtained from Sigma-Aldrich. FTC-casein and trypsin proteins were both obtained from ThermoFisher Scientific. Methanol, ethanol, ethyl acetate, tetrahydrofuran (THF), hexane and 2-butanone were acquired from ACS Chemicals and Fisher Scientific.

Media and Buffers. 1\% CTT (1\% casitone, $10 \mathrm{mM}$ Tris- $\mathrm{HCl}[\mathrm{pH} 7.6], 8 \mathrm{mM} \mathrm{MgSO} 4,1 \mathrm{mM}$ $\left.\mathrm{KH}_{2} \mathrm{PO}_{4}\right)$ was prepared from scratch. $\mathrm{LB}(10 \mathrm{~g} / \mathrm{L}$ tryptone, $10 \mathrm{~g} / \mathrm{L} \mathrm{NaCl}, 5 \mathrm{~g} / \mathrm{L}$ yeast extract) was prepared from a premix, which was purchased from Bio Basic. TSB (17 g/L casein peptone, 3 g/L soya peptone, 5g/L NaCl, $2.5 \mathrm{~g} / \mathrm{L} \mathrm{K} \mathrm{K}_{2} \mathrm{HPO}$, glucose $2.5 \mathrm{~g} / \mathrm{L}$ [pH 7.3]) premix was purchased from Sigma-Aldrich. NGM (3 $\mathrm{g} \mathrm{NaCl}, 2.5 \mathrm{~g}$ peptone $20 \mathrm{~g}$ agar, $1 \mathrm{~mL}$ of $5 \mathrm{mg} / \mathrm{mL}$ cholesterol in ethanol, $1 \mathrm{~mL}$ of $1 \mathrm{M} \mathrm{MgSO}_{4}, 25 \mathrm{~mL}$ of $1 \mathrm{M}$ [pH 6.0] $\mathrm{KPO}_{4}$ in $1 \mathrm{~L} \mathrm{H}_{2} \mathrm{O}$ ) was made from scratch. Worm M9 buffer (3 g/L KH $\left.2 \mathrm{PO}_{4}, 6 \mathrm{~g} / \mathrm{L} \mathrm{Na}_{2} \mathrm{HPO}_{4}, 5 \mathrm{~g} / \mathrm{L} \mathrm{NaCl}\right)$ was made from scratch. The TBS buffer used in the protease assays was made from scratch (25 mM tris, $0.15 \mathrm{M} \mathrm{NaCl}[\mathrm{pH} 7.2])$. The sodium phosphate buffer used in the CD assays as also prepared from scratch ( $\mathrm{pH} 7.0$, ionic strength $0.014 \mathrm{M})$.

Geosmin quantitation. A culture of $M$. xanthus DK1622 in stationary phase was diluted to an $\mathrm{OD}_{600}$ of 0.125 , then diluted 1:100 in fresh $1 \%$ CTT. Samples were left shaking at $30{ }^{\circ} \mathrm{C}$ and 225 rpm. Aliquots were drawn every 12-24 hrs until day 9. OD 600 measurements were made on a Varian Cary 100 Bio UV-vis spectrophotometer. Samples over an OD600 of 1.0 were diluted in fresh $1 \%$ CTT media to the $0.010-0.99$ range. After 7 days incubation clumping was observed 
256 and prior to measurements, cells were dispersed via passage through a serological pipette.

257 Geosmin extractions were made using a 1:1 ethyl acetate (EtOAc) extraction with M. xanthus

258 DK1622 bacterial culture. Ethyl acetate samples were sonicated, then centrifuged for $1 \mathrm{~min}$ at

$2593000 \mathrm{~g}$ to collect clean supernatant before injection for quanitification by gas chromatography-

260 mass spectrometry (GC-MS). To quantify media versus cytoplasmic geosmin the bacterial

261 culture was centrifuged at $3000 \mathrm{~g}$ for $2 \mathrm{~min}$. The supernatant was used to measure extracellular

262 geosmin as detailed above, while the intracellular/cytoplasmic geosmin concentration was

263 measured by exposing the pellet of $M$. xanthus cells to ethyl acetate, vortexing for 1 min, then

264 sonicating and centrifuging down for $1 \mathrm{~min}$ at $3000 \mathrm{~g}$. The GC-MS system (7890B GC coupled

265 to a 5977B MS, Agilent Technologies) was equipped with an autosampler and a split/splitless

266 inlet kept at $300^{\circ} \mathrm{C}$. Splitless injections $(1.0-3.0 \mu \mathrm{L})$ were made on a $60-\mathrm{m}$ DB-EUPAH $(0.25$

$267 \mathrm{~mm}$ ID x $25 \mu \mathrm{m}$ film thickness; Agilent Technologies) column with the oven kept isothermal (80

$268{ }^{\circ} \mathrm{C}$ ) for $8 \mathrm{~min}$, ramped to $300{ }^{\circ} \mathrm{C}$ at $15^{\circ} \mathrm{C} / \mathrm{min}$, and then held at that temperature for $5 \mathrm{~min}$. The

269 inlet was kept at $300{ }^{\circ} \mathrm{C}$ throughout. Helium flow rate was $1.2 \mathrm{~mL} / \mathrm{min}$, with a He septum purge

270 flow of $5 \mathrm{~mL} / \mathrm{min}$. Seven-level external calibration curves between 0.01 and $1.00 \mathrm{mg} / \mathrm{L}$ were

271 used for quantitation.

272 Geosmin MIC. Following CLSI guidelines for direct colony suspension testing ${ }^{51}$, bacterial

273 cultures were transferred to LB broth and adjusted to a final turbidity equivalent to a 0.5

274 McFarland standard $\left(1.5 \times 10^{8} \mathrm{CFU} / \mathrm{mL}\right)$. Bacteria were then mixed 1:1 with $( \pm)$-geosmin in 96-

275 well plates, then incubated at $30^{\circ} \mathrm{C}$ for $20-24 \mathrm{hr}$. Methanol was used as a control. The MIC was

276 defined as the concentration sufficient to inhibit bacterial growth as evaluated by the naked eye.

277 After initial tests at concentrations similar to the level produced by M. xanthus DK1622 failed to 
278 inhibit growth the quantity was increased, until the methanol used to solubilize the high geosmin

279 concentrations began to impede growth.

Effect of geosmin on BSA thermal denaturation. CD analyses were made using a Jasco J-715

281 Spectropolarimeter. The cuvette width was $0.2 \mathrm{~cm}$. The BSA concentration was $1.25 \mu \mathrm{M}$ for all

282 experimental and control assays. Fresh protein samples were prepared before each experiment

283 and kept on ice. The (-)-geosmin concentration was $0.18 \mathrm{mM}$ for the experimental assay and the

284 SDS concentration was $0.75 \mathrm{mM}$. All samples were diluted in PBS ${ }^{52,53}$. Subtractions and

285 smoothing were made using Jasco J-715 software using controls of each chemical in PBS

286 exclusively. Elevated temperature analysis was made at $80^{\circ} \mathrm{C}$. The wavelength window

287 measured was from 200-240 nm. Five scans were made for each measurement. Experiments

288 were run in triplicate before data analysis using the Jasco J-715 instrument. Varying temperature

289 analysis was made at a wavelength of $208.6 \mathrm{~nm}$ and a heating/cooling rate of $1{ }^{\circ} \mathrm{C} / \mathrm{min}$.

290 Protease activity assay. A Pierce ${ }^{\mathrm{TM}}$ Fluorescent Protease Assay Kit was purchased from

291 Thermo Scientific ${ }^{\mathrm{TM}}$. The kit contained FTC-casein, n-tosyl-L-phenylalanine chloromethyl

292 ketone (TPCK) treated trypsin standard and a tris-buffered saline (TBS) buffer pack ${ }^{54}$.

293 As per the product sheets instructions ${ }^{54}$, FTC-casein was diluted a $5 \mathrm{mg} / \mathrm{mL}$ stock solution with

294 ultrapure water. One $20 \mu \mathrm{L}$ aliquot of the stock solution was diluted 1:500 in TBS to a final

295 volume of $10 \mathrm{~mL}$ and concentration of $0.01 \mathrm{mg} / \mathrm{mL}$. A $20 \mu \mathrm{L}$ aliquot of Trypsin stock solution

296 (TSS) of $50 \mathrm{mg} / \mathrm{mL}$ was diluted to $1 \mathrm{mg} / \mathrm{mL}$ in TBS. To obtain the extracellular proteases of $M$.

297 xanthus DK1622 absent geosmin the supernatant of a 10-day culture was extracted with EtOAc

298 and the organic layer discarded. A 50\% protease solution in TBS buffer was used and was kept

299 in ice with FTC-casein and trypsin. Each fluorometric assay was measured using a Varian Cary

300 Eclipse Fluorescence Spectrophotometer at $\lambda_{\text {excitation }}=494 \mathrm{~nm}$, and $\lambda_{\text {emission }}=521 \mathrm{~nm}$. The 
301 experiments were made with and without the presence of $( \pm)$-geosmin $(1 \mathrm{mg} / \mathrm{L})$ to evaluate the

302 effect of $( \pm)$-geosmin on the activity of the proteases. Methanol was used as a negative control.

303 Chemotaxis assay. Chemotaxis experiment was made following Bargmann et al ${ }^{55}$. On an NGM

304 plate $1 \mu \mathrm{L}$ of $(-)$-geosmin at the designated concentration was placed at $1 \mathrm{~cm}$ from one end of the 305 plate, and on the other symmetrical opposite end, $1 \mu \mathrm{L}$ of control was added (nanopure water). 1

$306 \mu \mathrm{L}$ of $1 \mathrm{M}$ levamisole was added to each drop before drying them adjacent to a flame for 20-

307 30min. Pure 2-butanone was used as a positive control ${ }^{56}$. N2 adult C. elegans were washed 3

308 times in worm M9 buffer before addition at the centre of the plates $(n=50)$. The plates were then

309 incubated at room temperature for $1 \mathrm{hr}$ before chemotaxis index calculation.

310 Behavioural assay. NGM agar with and without $0.54 \mu \mathrm{g} / \mathrm{mL}(-)$-geosmin was poured into 24

311 well plates. Three adult C. elegans were added to each well and were video-taped for $10 \mathrm{~min}$

312 using a system that uses NIS Imaging BR version 3 software hooked up to a DSFilc camera on a

313 NIKON SMZ1500 microscope. The track line \% (TL\% =

$314 \quad \frac{\text { Distance from first to current point }(D 2 S)}{\text { Length from first to current point (Len) }} * 100$ ) was calculated using Imaris $9.5^{57}$, data processed

315 with a custom-built python script (File S6). Briefly, the script read the .xls files produced by

316 Imaris particle tracking analysis, split the data into five two-minute segments, then extracted

317 results for the track length and displacement of each worm for track line percentage

318 determination. Videos were analysed using WormLab software 2020.1.1 58 to generate the

319 peristaltic speed $(\mu \mathrm{m} / \mathrm{s})$ and the head movement periodicity $(\mu \mathrm{m})$ of the worms. Peristaltic speed

320 is defined as peristaltic track length, the length of the track made by the worm during its

321 movement, divided over time. Head movement periodicity is the wavelength of the sinusoidal

322 wave created by tracing the head of the worms as they crawl. Worms that lodged in crevices and 
ceased moving were removed prior to analysis. Data was processed using Microsoft Excel 2011. Experiments were conducted in triplicate.

Predation assay. $40 \mu \mathrm{L}$ of $S$. coelicolor $\left(\mathrm{OD}_{600}=0.4-0.6\right)$ or M. xanthus $\left(\mathrm{OD}_{600}=0.2-0.3\right)$ was added to the center of a $5 \mathrm{~cm}$ diameter NGM plate. The liquid was allowed to dry and the plates were then incubated at $30^{\circ} \mathrm{C}$ ( 7 days for $S$. coelicolor and 3 days for $M$. xanthus). Ten adult hermaphrodite $C$. elegans were then added at 2-5 $\mathrm{mm}$ away from the bacterial colony. Quantification of the worms inside and outside of the bacteria was made at T=0,2, 4 and $24 \mathrm{hrs}$. Each experiment was conducted in at least triplicate.

Terpene add-in assay. Add-in experiments were made using S. coelicolor J2192, following the same procedure as in the predation assays with the following modification. One hour prior to the addition of $C$. elegans $40 \mu \mathrm{L}$ of (-)-geosmin $(2.25 \mu \mathrm{g} / \mathrm{mL}),(-)-2$-methylisoborneol $(40 \mu \mathrm{g} / \mathrm{mL})$, or both was added to the bacterial colony and allowed to dry. Autoclaved nanopure $\mathrm{H}_{2} \mathrm{O}$ was used as a negative control. Triplicates of each added compound were performed with the addition of 10 adult hermaphrodite N2 C. elegans $(n=30)$. Quantification was performed as per the predation assay.

C. elegans lethality assay. Solutions of (-)-geosmin $(0.54,5.4,54 \mu \mathrm{g} / \mathrm{mL})$ and 2-MIB $(1.5,15$, $150 \mu \mathrm{g} / \mathrm{mL}$ ) in LB broth were added to 24-well plates containing either NGM or NGM with $E$. coli $\mathrm{OP} 50$ as per H. Xiong et al. ${ }^{59}$. LB broth was used as a negative control and a sodium hypochlorite solution $(2.625 \mathrm{mg} / \mathrm{mL})$ in LB broth was used as a positive control. The plates were incubated overnight at RT. Age synchronized plates of adult N2 worms were then washed in worm M9 buffer, dried on NGM plates, then added to each well $(n=5)$. Lack of response to touch stimuli was used to presume death. The number of dead C. elegans was quantified at $\mathrm{T}=$ 0, 2, 4 and 24 hrs. Experiments were run in triplicate. 
346 Synthesis of 2-MIB. To a solution of (1R)-(+)-camphor (3.3 mmols) in anhydrous

347 tetrahydrofuran $(0.2 \mathrm{M})$ at $0{ }^{\circ} \mathrm{C}$ was added methylmagnesium bromide (4.95 mmols, $\left.3 \mathrm{M}\right)$. The

348 reaction was then heated to reflux for 10 hours, before being quenched with a saturated solution

349 of ammonium chloride in water. The THF was removed in vacuo and the remaining solution was

350 extracted three times with EtOAc. The organic layers were then pooled and extracted with brine,

351 then dried with sodium sulfate. The organic solvent was then removed in vacuo to give a white

352 solid. (325.8 mg, $58.70 \%)$. The crude mixture was then purified by flash chromatography (12\%

353 EtOAc in hexanes) to give the title compound as a white solid (48.7 $\mathrm{mg}, 8.77 \%$ yield). ${ }^{1} \mathrm{H}$ NMR

$354\left(500 \mathrm{MHz}, \mathrm{CDCl}_{3}\right) \delta 2.07(\mathrm{dt}, 1 \mathrm{H}, J=3.72 \mathrm{~Hz}, 13.08 \mathrm{~Hz}), 1.70(\mathrm{~m}, 2 \mathrm{H}), 1.39(\mathrm{~m}, 4 \mathrm{H}), 1.24(\mathrm{~s}$,

$3553 \mathrm{H}), 1.10(\mathrm{~s}, 3 \mathrm{H}), 0.87(\mathrm{~s}, 3 \mathrm{H}), 0.85(\mathrm{~s}, 3 \mathrm{H}) .{ }^{13} \mathrm{C} \mathrm{NMR}\left(125 \mathrm{MHz}, \mathrm{CDCl}_{3}\right) \delta$ 79.6, 51.9, 48.9,

$356 \quad 47.3,45.4,31.3,27.0,26.8,21.4,21.2,9.9$.

357 Statistical analysis. All statistical analyses were performed using student T-test calculations

358 with two-tailed distribution and unequal variance. Statistical significance of $P<0.05$ was noted

359 as a red box in Figure 1D and as $*$ for $P<0.05$ or $* *$ for $P<0.001$ in Figure 2A-D. All replicates

360 are distinct samples (biological replicates). Data was visualized with GraphPad Prism 9.0. 


\section{References}

364

1. Gerber, N. N. \& Lechevalier, H. A. Geosmin, an Earthy-Smelling Substance Isolated from Actinomycetes. Appl. Microbiol. 13, 935-938 (1965).

2. Reichenbach, H. The ecology of the myxobacteria. Environ. Microbiol. 1, 15-21 (1999).

3. Kurtböke, D. I. Ecology and Habitat Distribution of Actinobacteria. in Biology and Biotechnology of Actinobacteria (eds. Wink, J., Mohammadipanah, F. \& Hamedi, J.) 123-149 (Springer International Publishing, 2017). doi:10.1007/978-3-319-60339-1_6.

4. Jüttner, F. \& Watson, S. B. Biochemical and Ecological Control of Geosmin and 2-Methylisoborneol in Source Waters. Appl. Environ. Microbiol. 73, 4395-4406 (2007).

5. Lukassen, M. B. et al. Microbial Production of the Off-Flavor Geosmin in Tilapia Production in Brazilian Water Reservoirs: Importance of Bacteria in the Intestine and Other Fish-Associated Environments. Front. Microbiol. 10, (2019).

6. Mattheis, J. P. \& Roberts, R. G. Identification of geosmin as a volatile metabolite of Penicillium expansum. Appl. Environ. Microbiol. 58, 3170-3172 (1992).

7. Breheret, S., Talou, T., Rapior, S. \& Bessière, J.-M. Geosmin, a sesquiterpenoid compound responsible for the musty-earthy odor of Cortinarius herculeus, Cystoderma amianthinum, and Cy. carcharias. Mycologia 91, 117-120 (1999).

8. Melo, N. et al. Geosmin Attracts Aedes aegypti Mosquitoes to Oviposition Sites. Curr. Biol. 30, 127134.e5 (2020).

9. Citron, C. A., Gleitzmann, J., Laurenzano, G., Pukall, R. \& Dickschat, J. S. Terpenoids are Widespread in Actinomycetes: A Correlation of Secondary Metabolism and Genome Data. ChemBioChem 13, 202-214 (2012).

10. Martín-Sánchez, L. et al. Phylogenomic analyses and distribution of terpene synthases among Streptomyces. Beilstein J. Org. Chem. 15, 1181-1193 (2019). 
11. Yamada, Y. et al. Terpene synthases are widely distributed in bacteria. Proc. Natl. Acad. Sci. 112, 857-862 (2015).

12. Churro, C., Semedo-Aguiar, A. P., Silva, A. D., Pereira-Leal, J. B. \& Leite, R. B. A novel cyanobacterial geosmin producer, revising GeoA distribution and dispersion patterns in Bacteria. Sci. Rep. 10, (2020).

13. Dickschat, J. S., Bode, H. B., Mahmud, T., Müller, R. \& Schulz, S. A Novel Type of Geosmin Biosynthesis in Myxobacteria. J. Org. Chem. 70, 5174-5182 (2005).

14. Stensmyr, M. C. et al. A Conserved Dedicated Olfactory Circuit for Detecting Harmful Microbes in Drosophila. Cell 151, 1345-1357 (2012).

15. Huang, H. et al. The nesting preference of an invasive ant is associated with the cues produced by actinobacteria in soil. PLOS Pathog. 16, e1008800 (2020).

16. Becher, P. G. et al. Developmentally regulated volatiles geosmin and 2-methylisoborneol attract a soil arthropod to Streptomyces bacteria promoting spore dispersal. Nat. Microbiol. 5, 821-829 (2020).

17. Bérdy, J. Thoughts and facts about antibiotics: where we are now and where we are heading. J. Antibiot. (Tokyo) 65, 385-395 (2012).

18. Cragg, G. M. \& Pezzuto, J. M. Natural Products as a Vital Source for the Discovery of Cancer Chemotherapeutic and Chemopreventive Agents. Med. Princ. Pract. 25, 41-59 (2016).

19. Jousset, A. Ecological and evolutive implications of bacterial defences against predators. Environ. Microbiol. 14, 1830-1843 (2012).

20. Pérez, J. et al. Myxococcus xanthus induces actinorhodin overproduction and aerial mycelium formation by Streptomyces coelicolor. Microb. Biotechnol. 4, 175-183 (2011). parasitic nematodes. J. Chem. Ecol. 19, 159-173 (1993). 
411 22. Wiener, P. Experimental studies on the ecological role of antibiotic production in bacteria. Evol. Ecol. 10, 405-421 (1996).

413 23. Saporito, R. A., Zuercher, R., Roberts, M., Gerow, K. G. \& Donnelly, M. A. Experimental Evidence for 414 Aposematism in the Dendrobatid Poison Frog Oophaga pumilio. Copeia 2007, 1006-1011 (2007).

415 24. Alatalo, R. V. \& Mappes, J. Tracking the evolution of warning signals. Nature 382, 708-710 (1996).

416 25. Exnerová, A. et al. Avoidance of aposematic prey in European tits (Paridae): learned or innate?

417 Behav. Ecol. 18, 148-156 (2007).

418 26. Jones, R. S., Fenton, A. \& Speed, M. P. 'Parasite-induced aposematism' protects entomopathogenic nematode parasites against invertebrate enemies. Behav. Ecol. 27, 645-651 (2016).

27. Kumbhar, C., Mudliar, P., Bhatia, L., Kshirsagar, A. \& Watve, M. Widespread predatory abilities in the genus Streptomyces. Arch. Microbiol. 196, 235-248 (2014).

422

28. Berleman, J. E. et al. The lethal cargo of Myxococcus xanthus outer membrane vesicles. Front. Microbiol. 5, (2014).

29. White, J. G., Southgate, E., Thomson, J. N. \& Brenner, S. The structure of the ventral nerve cord of Caenorhabditis elegans. Philos. Trans. R. Soc. Lond. B Biol. Sci. 275, 327-348 (1976).

30. Jiang, Y. et al. Nematode grazing promotes bacterial community dynamics in soil at the aggregate level. ISME J. 11, 2705-2717 (2017).

31. van den Hoogen, J. et al. Soil nematode abundance and functional group composition at a global scale. Nature 572, 194-198 (2019). Behavior in C. elegans. PLOS ONE 4, e7584 (2009). domain chemosensory receptor. eLife 6, e23770 (2017). 
34. Lans, H., Rademakers, S. \& Jansen, G. A Network of Stimulatory and Inhibitory Ga-Subunits Regulates Olfaction in Caenorhabditis elegans. Genetics 167, 1677-1687 (2004).

35. Milward, K., Busch, K. E., Murphy, R. J., Bono, M. de \& Olofsson, B. Neuronal and molecular substrates for optimal foraging in Caenorhabditis elegans. Proc. Natl. Acad. Sci. 108, 20672-20677 (2011).

36. Appleby, P. A. A model of chemotaxis and associative learning in C. elegans. Biol. Cybern. 106, 373387 (2012).

37. Jiang, J., He, X. \& Cane, D. E. Biosynthesis of the earthy odorant geosmin by a bifunctional Streptomyces coelicolor enzyme. Nat. Chem. Biol. 3, 711-715 (2007).

38. Mak, S. \& Nodwell, J. R. Actinorhodin is a redox-active antibiotic with a complex mode of action against Gram-positive cells. Mol. Microbiol. 106, 597-613 (2017).

39. Seto, H., Watanabe, H. \& Furihata, K. Simultaneous operation of the mevalonate and nonmevalonate pathways in the biosynthesis of isopentenly diphosphate in Streptomyces aeriouvifer. Tetrahedron Lett. 37, 7979-7982 (1996).

40. Dairi, T. Studies on Biosynthetic Genes and Enzymes of Isoprenoids Produced by Actinomycetes. J. Antibiot. (Tokyo) 58, 227-243 (2005).

41. Alghanmi, H. A., Alkam, F. M. \& AL-Taee, M. M. Effect of light and temperature on new cyanobacteria producers for geosmin and 2-methylisoborneol. J. Appl. Phycol. 30, 319-328 (2018).

42. Vazquez-Martinez, M. G. et al. Cyanobacteria associated with Anopheles albimanus (Diptera: 
45. Chouteau, M., Arias, M. \& Joron, M. Warning signals are under positive frequency-dependent selection in nature. Proc. Natl. Acad. Sci. 113, 2164-2169 (2016).

46. Jousset, A. et al. Predators promote defence of rhizosphere bacterial populations by selective feeding on non-toxic cheaters. ISME J. 3, 666-674 (2009).

47. Servedio, M. R. The Effects of Predator Learning, Forgetting, and Recognition Errors on the Evolution of Warning Coloration. Evolution 54, 751-763 (2000).

48. De la Fuente, I. M. et al. Evidence of conditioned behavior in amoebae. Nat. Commun. 10, 1-12 (2019).

49. Nishijima, S. \& Maruyama, I. N. Appetitive Olfactory Learning and Long-Term Associative Memory in Caenorhabditis elegans. Front. Behav. Neurosci. 11, (2017).

50. Stiernagle, T. Maintenance of C. elegans. WormBook (2006) doi:10.1895/wormbook.1.101.1.

51. Weinstein, M. P. \& Clinical and Laboratory Standards Institute. Performance standards for antimicrobial susceptibility testing. (2019).

52. Moriyama, Y. et al. Secondary Structural Change of Bovine Serum Albumin in Thermal Denaturation up to $130{ }^{\circ} \mathrm{C}$ and Protective Effect of Sodium Dodecyl Sulfate on the Change. J. Phys. Chem. B 112,

53. Takeda, K., Miura, M. \& Takagi, T. Stepwise formation of complexes between sodium dodecyl sulfate and bovine serum albumin detected by measurements of electric conductivity, binding isotherm, and circular dichroism. J. Colloid Interface Sci. 82, 38-44 (1981).

54. Pierce Biotechnology. Pierce Fluorescent Protease Assay Kit. (2014). in C. elegans. Cell 74, 515-527 (1993). Olfaction (ed. Menini, A.) (CRC Press/Taylor \& Francis, 2010). 
bioRxiv preprint doi: https://doi.org/10.1101/2021.03.09.434661; this version posted March 10, 2021. The copyright holder for this preprint (which was not certified by peer review) is the author/funder. All rights reserved. No reuse allowed without permission.

481 57. Imaris. (BitPlane).

482 58. WormLab. (MBF Bioscience).

483 59. Xiong, H., Pears, C. \& Woollard, A. An enhanced C. elegans based platform for toxicity assessment. Sci. Rep. 7, 9839 (2017).

485

486 


\section{Acknowledgements}

488 We thank P. Prevost and the Forgione lab for assistance with the synthesis of 2-methylisoborneol; $\mathrm{K}$.

489 Flärdh for supplying S. coelicolor M145, J3003, and J2192; E. Despland for microscopy support; L.K.

490 Freeman for discussions and feedback. Imaging support was provided by the Concordia Centre for

491 Microscopy and Cellular Imaging, while CD and fluorimetry was performed with the assistance of the

492 Concordia Integrated Platform for Biomolecular Function, Interactions and Structure. Funding: This work

493 was supported by funds from the National Sciences and Engineering Research Council (NSERC) and the

494 Fonds de Recherche du Québec- Nature et Technologie (FRQNT).

\section{Author Contributions}

497 BLF and LZ conceived the study. LZ performed all listed experiments with assistance from Al and YG (GC-

$498 \mathrm{MS}$ ); IO, KM and AP (C. elegans); CL (microscopy). IO and AP helped perform the behavioural, predation

499 (S. coelicolor) and terpene add-in assays. KM and AP aided with the chemotaxis assay. CL prepared the

500 python script. BLF and LZ prepared the manuscript, with feedback from all authors.

501

\section{Competing Interests}

$503 \quad$ None to declare.

\section{Data and Material Availability}

506 All data is available in the main text or the supplementary materials. 
bioRxiv preprint doi: https://doi.org/10.1101/2021.03.09.434661; this version posted March 10, 2021. The copyright holder for this preprint (which was not certified by peer review) is the author/funder. All rights reserved. No reuse allowed without permission.

\section{Supporting Online Material}

509 Supporting material is available online at BioRxiv.org

510 Materials and Methods

511 Figures S1 to S3

$512 \quad$ Tables S1 to S4

513 Files S1 to S6

514 
A<smiles>C[C@H]1CCC[C@@]2(C)CCCC[C@]12O</smiles>

$(-)-$-Geosmin

B

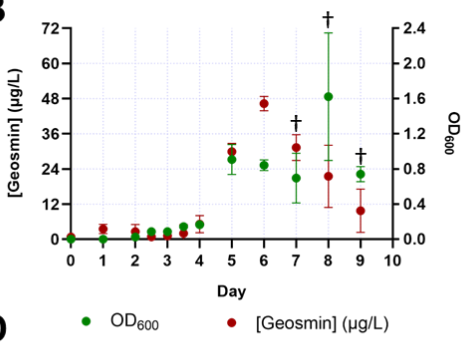

C

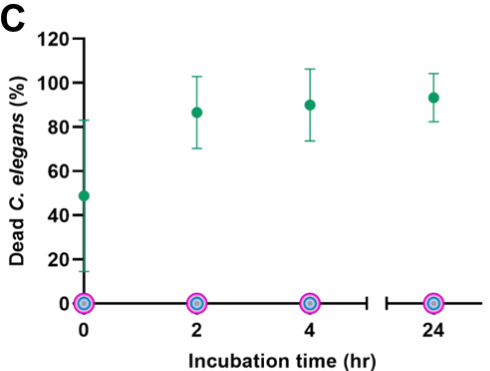

- Bleach $(2.625 \mathrm{mg} / \mathrm{mL})$

- Geosmin $(54 \mathrm{ug} / \mathrm{mL})$ 2-MIB $(150 \mathrm{ug} / \mathrm{mL})$

\begin{tabular}{|c|c|c|c|c|}
\hline C. elegans & Sensory Deficiency & $\begin{array}{c}\text { Track Line } \\
(\%)\end{array}$ & $\begin{array}{c}\text { Peristaltic } \\
\text { Speed }(\mu \mathrm{m} / \mathrm{s})\end{array}$ & $\begin{array}{c}\text { Periodicity } \\
(\mu \mathrm{m})\end{array}$ \\
\hline N2 & Wild type & & 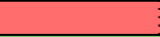 & \\
\hline BR5514 & $\mathrm{AFD}, \mathrm{ASE}$ and $\mathrm{AWC}$ & & & \\
\hline CE1248 & AWA & & & \\
\hline CX2065 & AWB and partial AWC & & & \\
\hline CX2205 & Olfactory system & & & \\
\hline CX5893 & AWC & & & \\
\hline NL2105 & Chemosensation & & 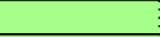 & \\
\hline PR674 & $\mathrm{ASE}$ & & $P=$ & $P \geq 0.05$ \\
\hline
\end{tabular}

$517 \quad$ Figure 1: Geosmin production and toxicity.

518 A, Chemical structures of geosmin and 2-methylisoborneol.

519 B, Growth curve and geosmin production of M. xanthus DK1622 in 1\% CTT. Geosmin concentrations 520 were determined via GC-MS, with the aid of a calibration curve derived from solutions of authentic 521 geosmin. + Cells began to clump at day 7 , complicating $\mathrm{OD}_{600}$ measurements.

522 C, Viability of adult $C$. elegans hermaphrodites in the presence of geosmin, 2-methylisoborneol and 523 bleach. Worms non-responsive to touch stimuli were declared dead. Experiments were conducted in 524 triplicate with five adult $C$. elegans per well $(n=15)$.

525 D, Comparison of the movement of adult C. elegans hermaphrodites on NGM and NGM-geosmin (0.54 $\mu \mathrm{g} / \mathrm{mL}$ ) plates, quantified with Imaris (track line) and WormLab (peristaltic speed, periodicity).

527 Significant differences between NGM and NGM-geosmin plates are represented by a red box $(P<0.05)$ 528 and non-significant differences by a green box $(P \geq 0.05)$. Experiments were conducted in triplicate with three worms per plate $(n=9)$. Full details are available in External Data Table 4. 
A

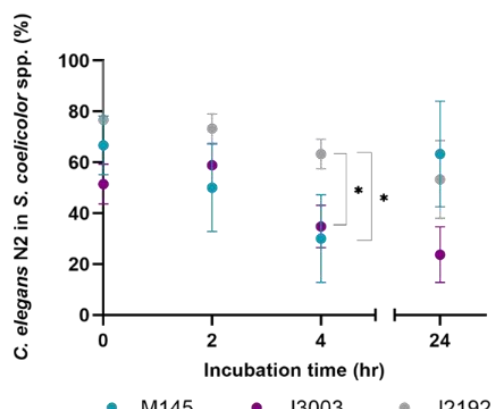

C ळ

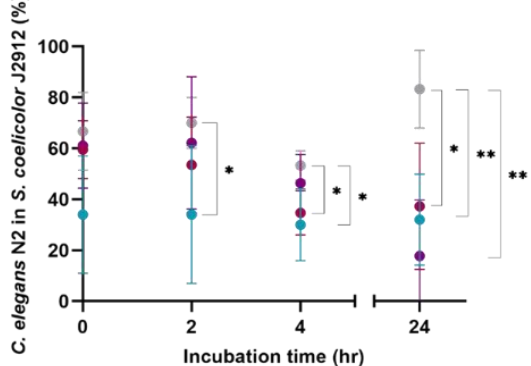

- Geosmin $\quad$ 2-MIB

- Geosmin and 2-MIB • $\mathrm{ddH}_{2} \mathrm{O}$
B ळ

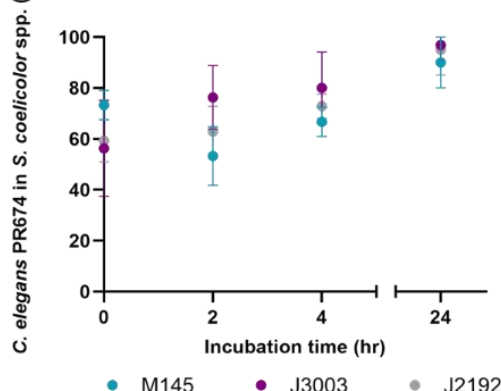

D

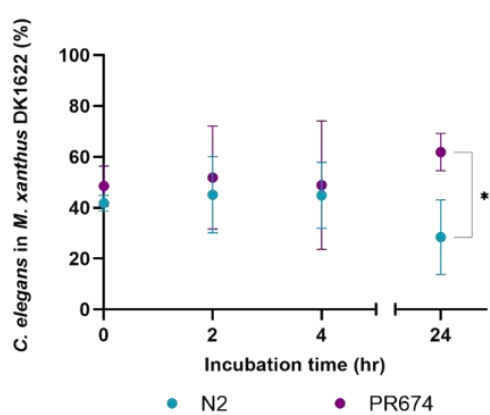

$532 \quad$ Figure 2: Predation of S. coelicolor and M. xanthus by C. elegans.

533 A, Proportion of adult C. elegans N2 worms in colonies of S. coelicolor M145 (WT), J3003 ( $\triangle$ geoA) and

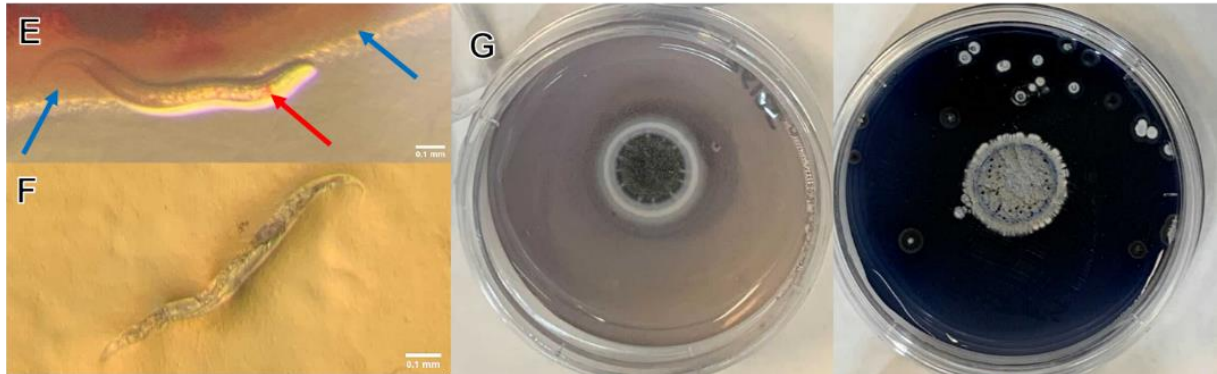
$\mathrm{J} 2192(\triangle g e o A \triangle m i b A B)$ as a function of time.

B, Proportion of $C$. elegans PR674 (che-1(p674), ASE deficient) worms in colonies of S. coelicolor M145 (WT), J3003 ( $\triangle g e o A)$ and $\mathrm{J} 2192(\triangle g e o A \triangle m i b A B)$ as a function of time. C, Proportion of $C$. elegans N2 worms in colonies of S. coelicolor J2912 that were pre-treated with geosmin, 2-methylisoborneol, or distilled, deionized water as a function of time.

D, Proportion of C. elegans N2 and PR674 worms in colonies of M. xanthus DK1622 as a function of time.

E, Consumption of S. coelicolor by C. elegans. Blue arrows indicate the bacterial colony, the red arrow

542 F, Production of spores and actinorhodin by S. coelicolor in the absence (left) or presence (right) of $C$. 543 elegans. 10 day cultures, room temperature.

544 G, C. elegans on a $M$. xanthus lawn. Worms became translucent prior to death and were ultimately 545 digested by the bacteria. 
bioRxiv preprint doi: https://doi.org/10.1101/2021.03.09.434661; this version posted March 10, 2021. The copyright holder for this preprint (which was not certified by peer review) is the author/funder. All rights reserved. No reuse allowed without permission.

546 All nematode experiments were run in triplicate, with ten adult hermaphrodites per study ( $\mathrm{n}=30)$.

547 Worms were grown on E. coli OP50 and starved for 20 minutes prior to addition to S. coelicolor or $M$.

548 xanthus. Statistically significant deviations from $\mathrm{J} 2192(\mathrm{~A}, \mathrm{~B}), \mathrm{H}_{2} \mathrm{O}(\mathrm{C})$, or wildtype (D) are indicated by * $549 \quad(P<0.05)$ or $* *(P<0.01)$. Representative images are shown. 